\title{
Neonatal Psychology: Theories and Practice
}

\author{
Elvidina N. Adamson-Macedo PhD CPsychol AFBPsS ${ }^{1}$
}

DOI: http://dx.doi.org/10.7322/jhgd.119236

The reality was that in the 1970s and still part of 1980s in the UK, parents were not permitted to visit their preterm babies for more than a few hours in the morning and later in the afternoon/evening. In addition they were not encouraged to handle/touch their babies for fear of infection. Situation was even more depressing in other parts of the world like e.g. Bangkok where mothers could not go into the special care unit and only saw their babies through the glass partition. Other countries such as Romania and China had no special provision for babies born preterm; it seemed that they adopted a 'let nature takes its course’ approach.

In 1979 and 1980s when I started my Doctorate (University of London, Bedford College) and the work in London/home counties Hospitals there were no psychologists attached to Special Care Baby Unit (SCBUs). Psychologists working directly with hospitalised preterm babies and their parents were rare; usually they were research students engaged on data collection. I was blessed by having an extraordinary Supervisor - the late Prof. Brian Foss- he had connections with SCBUs colleagues and passion to provide opportunities to foreign students; he organised for me to start work firstly with the most progressive Unit in the UK at High Wycombe General Hospital. It was the first Unit with room-in for mothers to stay close to their babies day and night and an incredible progressive neonatologist and human being leading it - the late Dr. D. G. His kindness, guidance and support at the very beginning are unforgettable.

After High Wycombe and Queen Charlotte's Units I focused my efforts only at St. George's Hospital Special Care Baby Unit (SCBU). I was fortunate that despite my foreign accent and my decision to work with the sense of touch only, medical professional and nurses were, 'cau- tious' but welcoming and very supportive. The parents were so welcoming that many of them became long lasting amazing friends.

Medical research at that time was very much against handling babies, which was translated into considering that handling/touching babies in incubators were harmful. So my first step was to differentiate handling from TOUCH. Handling involves touching but touch does not need to involve handling.

My second step was to challenge the concepts that hospitalised preterm babies were either over stimulated or under stimulated; my observations of the babies themselves were teaching me that they were inappropriately stimulated, as far as ‘supplemental care’ was concerned. Being TOUCH the first sensory system to appear and develop we should 'synchronise' with nature to improve quality of care; by timing our psychological intervention to that particular time in baby's development we could indeed be "doing the right thing in the right way at the right time and for the right reason in order to obtain a desired outcome...” paraphrasing Nabialczyk-Chalupowski from her excellent Editorial when referring to the concept of quality as being “... as old as recorded human history”. ${ }^{1}$

It was the very beginning of developing the first sensory nurturing care programme, implement it and evaluate its developmental effects in hospitalised preterm babies. This was the birth of TAC-TIC (Touching And Caressing - Tender In Caring) ${ }^{2}$ programme and the commencement of a long-standing line of original research with hospitalised preterm non-ventilated (1980s, 1990s, 2000s) and ventilated ones (1980s and 1990s).

This Editorial focuses on the path of a brand new sub-discipline, which initially I called Neonatal Psychology. ${ }^{3,4}$ We had developed, implemented and evaluated the

1 Emeritus Professor of Maternal-Infant Mental Health (University of Wolverhampton [UK], Retired [CHSCl], formerly School of Health) Corresponding author: Elvidina N. Adamson-Macedo - E-mail: enadamsonmacedo9@gmail.com

Suggested citation: Adamsom-Macedo EN. Neonatal Psychology: Theories and Practice. J Hum Growth Dev. $26(2)$ : $129-132$. 
effects of the first systematic unimodal sensory nurturing care programme (TAC-TIC) for hospitalised preterms; we had identified the most appropriate theory - within Development Psychology- to become the theoretical framework for such unique care programme.

We had identified Gottieb's 5 as the most appropriate system theory. We proposed a three-dimensional system model to explain babies' experiences before, during and after receiving the care programme, which, for the first time, could be visualised and quantified. ${ }^{6-8}$ Furthermore it could continually monitor the quality of the psychological care being given to individual babies by observing and measuring their immediate responses. Later same model was adapted to be used with adults. ${ }^{9}$

Neonatology is a well-established sub-discipline of medicine, concerned with the medical care of the newborn; of particular importance are the at-risk newborn or premature infants. Neonatology is a hospital-based specialty usually practiced in Neonatal Intensive Care Units (NICU). Neonatology in the 1970s and 1980s was developing very rapidly and acquiring multidisciplinary connotations; this progress has shown the importance of bringing together the knowledge and experiences of the medical professions, health professionals, psychologists and parents to improve the quality of physical and psychological care of the newborn; this is particularly true for hospitalised preterm neonates.

Thus by expanding frontiers of Neonatology - as also neonatal nurses were being trained - the opportunity was created for psychology to make an effective contribution to both the theory and the quality of care of the preterm neonate viewed by myself as a unique, emergent, coactional and hierarchical human being, as an open system. The formal framework for this initially was called Neonatal Psychology. ${ }^{3}$

There are, of course, many definitions of psychology but the one given by W. James in 1890 defies improvement: "the science of mental life, both its phenomena and of their conditions. The phenomena are such things as we call feelings, desires, cognition, reasoning, decisions and the like”. ${ }^{3}$ For me the preterm baby has a mind. ${ }^{4}$

There are also many system theories used to explain development such as ecological, transactional, contextual, interactive, probabilistic-epigenetic, individual-sociological, and structural-behavioural. The one I chose to define Neonatal Psychology is the system theory of G. Gottlieb. ${ }^{5}$ So based on W James and Gottlieb I defined Neonatal Psychology as "the scientific study of the phenomena of mental life and the behaviour of the preterm neonate as an emergent, coactional, hierarchical system' ${ }^{3}$ Thereby stating the theoretical framework to systematically explain the psychoneurobiological development of the preterm neonate, particularly the hospitalised one, as an open system.

Central to this framework is the notion of horizontal (eg. genes to genes) and vertical (eg genes to environment) COACTIONS. ${ }^{5}$ In order to simplify visualisation of how such coactions could be detected the 'Equilibrium Model' ${ }^{6}$ was developed and used to test the hypothesis that given the appropriate care for the baby his/her organism is able to self-regulation and their behaviour, physiology and immune systems would respond in a positive spontaneous order thereby facilitating baby's development . What makes development happen is the relationship of ${ }^{2}$ or more components and not the components themselves.

By timing the environmental/psychological intervention with the baby's needs at that particular point in time the carer is 'synchronising' with babies' developmental need; then self-regulation is encouraged thus facilitating EQUILIBRIUM amongst the various systems of this fragile but resilient organism; in Gottlieb’s terminology we could say the 'appropriate' experiential canalization $^{5}$ was happening thus facilitating development. The importance of choosing the appropriate care programme is paramount; this is what all neonatologists (medical, nursing, physiotherapists and Psychologists) aim for to provide quality of care 1 . A clear example can be seen in our work that led to the systematization of neonatal psychoneuroimmunology.$^{6-8}$ I was privileged to work with amazing progressive neonatologists (doctors, nurses, midwife and fhisicaltherapy) at different hospitals and fascinating parents and grandparents.

My scientific passion has always been to innovate, develop, implement and evaluate quality psychological care programmes for the hospitalised preterm babies and their parents aiming to improve their chances of intact survival and a rich relationship with their parents from birth. Separation must be avoided. ${ }^{13}$ Therefore, with the establishment of Health Psychology in 1994 the time was appropriate for me to redefine neonatal Psychology into Neonatal Health Psychology (NNHP). Still using the same theoretical framework but defined as "the scientific study of biopsychosocial and behavioural processes in health, illness, and health care of the preterm (and fullterm) neonate during his/her first 28 days of life, and the relationshipMeasuring and monitoring are essential to ascertain the Quality of Care being it medical or psychological. The Scope 10 of NNHP cover three major areas, as follows:

1.Assessment procedures and Diagnostic methods;

2. Sensory nurturing interventions, including support for babies and their caregivers;

of such processes with later outcome.10-13.

3. Proposals for new paradigms. 
Thus the origins of NNHP can be traced along five paths, although 2, 3 and 4 are inevitably intermingled:

1. Prenatal and perinatal Psychology and Medici ${ }^{14}$

2. Neonatology ${ }^{15}$

3. Environmental Neonatology ${ }^{15}$

4. Environmental and Developmental Neonatology ${ }^{16}$

5. Neonatal Psychology ${ }^{3}$

As Nabialczyk-Chalupowski so well discussed the issue that despite accumulation of ten of thousands of publications there is no consensus as yet regarding the definition of the concept of quality of medical care. A great deal has been published also about the need for psychological quality care from birth. And yet despite advances in the care of these babies, preterm births continue to be a Public Health problem. Survival rates greatly improved but morbidity increases.

In short, we would like to think that in most units by now would have a neonatal psychologist attached to it but the reality is far from this one. Despite all advances and contributions of Psychology the number of psychologists attached to the NICU remains rare. Neonatal Health Psychology was taught to academic psycholo- gists attending the Development Psychology and Health Psychology courses where this author was teaching and conducting research - the University of Wolverhampton and Midland Hospitals- UK. In addition, courses at home and abroad and dissemination at International Conferences and/or research collaborations with Europe, Brasil and USA.

Any neonatal health professional can of course, use the theoretical framework briefly outlined here. Yes, there is still a lot of work to be done. New Neonatal Psychology courses must be developed and taught with a multidisciplinary team of neonatal health professionals including neonatologists at home and abroad.

Our recent research including maternal variables i.e. maternal self-efficacy ${ }^{17}$ during baby hospitalisation, used our scale ${ }^{18}$ of perceived self-efficacy of maternal parenting in Brazilian sample; ${ }^{19-20}$ the doors are open to continue the scientific journey of Neonatal Health Psychology and of its practice in the Neonatal Intensive and Special Care Units (NICUs/SCBUs) to provide, measure and monitor quality of psychological care from birth.

"New opinions are always suspected and usually opposed, without any other reason but because they are not already common.” (John Locke).

\section{REFERENCES}

1. Nabialczyk-Chalupowski M. Tracking the origins, defi ning and quantifying quality of care: can we reach a consensus. J Hum Growth Dev. 2016;26(2):133-8. DOI: http://dx.doi.org/10.7322/jhgd.119237

2. Macedo EN. Effects of very early Tactile Stimulation on very-low birthweight Infants - a 2-year follow-up study. (Unpublished doctoral dissertation) - University of London. Bedford College: 1984.

3. Adamson-Macedo EN. Neonatal Psychology: system development. In: Cockburn F. Advances in perinatal medicine. The Proceedings o the XV European Congress of Perinatal Medicine. The Parthenon Publishing Group. New York: 1997; p.292-302.

4. Adamson-Macedo EN. The Mind and body of the preterm neonate. Int J Prenatal Perinatal Psychol Med. 1998;10(4):439-6.

5. Gottlieb G. Individual Development and Evolution: The Genesis of Novel Behavior. Oxford University Press. New York: 1992.

6. Adamson-Macedo EN. Neonatal Psychoneuroimmunology: Emergence, scope and perspectives. Int J Prenatal Perinatal Psychol Med.1997;9(4):421-40.

7. Hayes JA, Adamson-Macedo EN, Perera S. The Mediating role of Cutaneous Sensitivity within Neonatal Psychoneuroimmunology. Neuro Endocrinol Lett. 2000;21(3):187-93.

8. Hayes JA, Adamson-Macedo EN, Perera S, Anderson J. Detection of secretory immunoglobulin A (SIgA) in saliva of ventilated and non-ventilated preterm neonates. Neuro Endocrinol Lett. 1999;20(1-2):109-13.

9. Bellingham-Young DA, Adamson-Macedo EN. The impact of birthweight on adult minor illness: a study on a sub-clinical population. J Hum Growth Dev. 2013;23(1):111-17. DOI: http://dx.doi.org/10.7322/jhgd.50416

10. Adamson-Macedo EN. Pathways in the Emergence of Neonatal Health Psychology (NNHP), and its scope Int J Prenatal Perinatal Psychol Med. 2000;12(1):15-39.

11. Adamson-Macedo EN. O Surgimento e os caminhos da Psicologia da Saúde Neonatal (PSN). In: Correa Filho L, Correa MEG, França PS. Novos olhares sobre a gestação e a criança até os 3 anos. saúde perinatal, educação e desenvolvimento do bebê. L. G. E. 2002; p.458-77.

12. Adamson-Macedo EN. Neonatal Psychology [NNHP]: Theories and practice. Neuro Endocrinol Lett. 2004;25(Suppl. 1):9-34.

13. Adamson-Macedo EN. Éviter la separation. In: Eliacheff C, Szejer M. Le bébé et les ruptures Séparation et exclusion. Paris: Albin Michel; 2003; p.154-69. 
14. Fedor-Freybergh PG, Vogel VML. Prenatal and Perinatal Psychology and Medicine, Encounter With the Unborn: Comprehensive Survey of Research and Practice. The Parthenon Publising Group. 1988.

15. Gottfried AW, Gaiter JL. Infant Stress Under Intensive Care: Environment Neonatology. Baltimore: University Park Press; 1985.

16. Wolke, D. Environmental and developmental neonatology. J Reproductive Infant Psychol. 1987;5(1):17-42. DOI: http://dx.doi.org/10.1080/02646838708403471

17. Bandura A. Self-effi cacy: The exercise of control. New York: Freeman; 1997.

18. Barnes CR, Adamson-Macedo EN. Perceived Parenting Self-Effi cacy (PMP S-E) of mothers who are breastfeeding hospitalized preterm neonates. Neuro Endocrinol Lett. 2004;25 (Suppl. 1):95-102.

19. Tristão RM, Neiva ER, Barnes CR, Adamson-Macedo EN. Validation of the scale of perceived self-effi cacy of maternal parenting in Brazilian sample. J Hum Growth Dev. 2015;25(3):277-86. DOI: http://dx.doi. org/10.7322/jhgd.96759 